\title{
Discussion on moment tensor solution and seismogenic structure of Ruichang-Yangxin earthquake on 10 September 2011*
}

\author{
Lifen Zhang ${ }^{1,2, \uparrow}$ Guichun Wei and Wulin Liao ${ }^{1}$ \\ ${ }^{1}$ Key Laboratory of Earthquake Geodesy, Institute of Seismology, China Earthquake Administration, \\ Wuhan 430071, China \\ 2 Institute of Geophysics, China Earthquake Administration, Beijing 100081, China
}

\begin{abstract}
Ruichang-Yangxin earthquake is another moderate earthquake in Yangxin-Jiujiang area since 2005 Jiujiang-Ruichang M5.7 earthquake. In order to more understand the seismic activities in this area, we study the moment tensor solution and the seismogenic structure of the Ruichang-Yangxin earthquake. Precise earthquake relocation shows that the mainshock occurred on the southwestern part of the NE-trending fault and aftershocks are distributed not only along the NE-trending fault but also along its conjugated NW-trending fault. By comprehensive analysis on the earthquake distribution, characteristics of isoseismal curve, focal mechanism, and regional structure characteristics, it is inferred that this earthquake is caused by the NE-trending Tanlu fault. In addition, it has close relationship with the conjugated NW-trending fault as well. Many researches have shown that the junction area is the earthquake-prone area, and should be paid more attention to. And our study also proves this viewpoint.
\end{abstract}

Key words: moment tensor inversion; Ruichang-Yangxin earthquake; seismogenic structure CLC number: P315.2 Document code: A

\section{Introduction}

On 10 September 2011 a moderate earthquake with M4.6 occurred in the intersection region of Ruichang city, Jiangxi province, and Yangxin city, Hubei province $\left(29.7^{\circ} \mathrm{N}, 115.4^{\circ} \mathrm{E}\right.$, determined by China Earthquake Networks Center). It is called RuichangYangxin earthquake, which is another medium-sized earthquake in this area since the Jiujiang-Ruichang M5.7 earthquake in 2005. Luckily, it did not cause great economic losses and casualties. However, has the stress field in this region with weak seismic background been changed? If it is so, what kind of changes occurred? What is the consequence? In order to answer these questions, an efficient way is to have a deeper understanding of the seismogenic fault. Likewise, this study is of great

\footnotetext{
${ }^{*}$ Received 13 April 2012; accepted in revised form 20 May 2012; published 10 June 2012.

+ Corresponding author. e-mail: zhanglf112@163.com

(C) The Seismological Society of China, Institute of Geophysics,

China Earthquake Administration, and Springer-Verlag Berlin Heidelberg 2012
}

significance to the seismic structure research in mideastern China and seismic hazard evaluation in the future.

\section{Tectonic setting}

Ruichang-Yangxin area is located in the transitional zone of Qinling-Dabie orogenic belt (QDB) and Yangtze platform (YZP). Therefore, this area is controlled by the two tectonic units. In addition, the epicenter of Ruichang-Yangxin earthquake is close to the junction of Tanlu fault (TLF) and Xiangfan-Guangji fault (XGF) (Figure 1). Both faults are regional deep faults. The NNE-SSW-trending TLF is one of the largest continental strike-slip faults in the world. And it is one of the major lithospheric discontinuities in eastern China as well. Till now, the spatial extent of this fault is still in discussion (Tang et al., 2003; Wan et al., 2009). And the common viewpoint is that this fault terminates in the north bank of Yangtze River. Another opinion is that Ganjiang fault (GJF) is the southern extension across 
Yangtze River of TLF. XGF is a NW-trending deep fracture, which is considered to be the boundary of QDB and YZP. Cui et al. (2005) put forward a new conception 'junction' or 'coupling fault' to explain the close relationship among TLF, XGF and GJF. The XGF shows tensional fracture, dextral strike slip and compression in order, and the junction zone in the Jiujiang-Ruichang area is sequentially characterized by tensile stress field, shear stress field and compressive stress field. In addition, it is found that the geological activities are affected by the two faults. In summary, the tectonic setting of Ruichang-Yangxin area is very special.
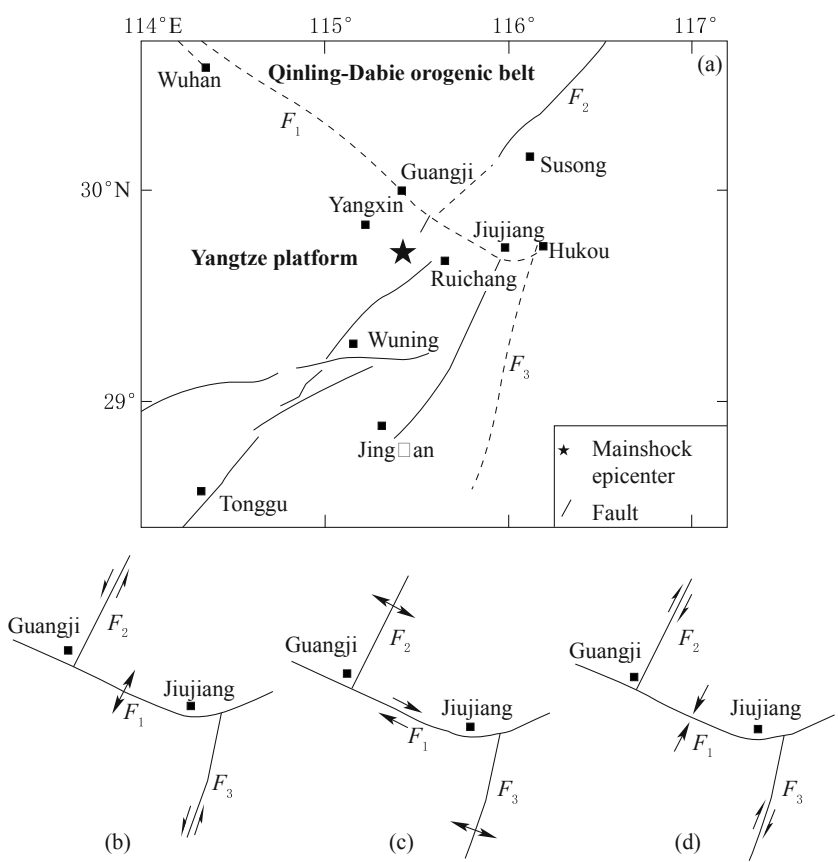

Figure 1 (a) Tectonic setting and sketch map of the Xiangfan-Guangji fault (XGF), Tanlu fault (TLF) and Ganjiang fault (GJF). (b) In $\mathrm{J}_{3}-\mathrm{K}_{1}$, TLF and GJF showed sinistral strike slip, XGF fault was characterized by NW-WNW-trending tensile fracturing. (c) From the end of $K_{1}$ to $K_{2}$, TLF and GJF showed extension, XGF was characterized by NW-WNW-trending and dextral translation, and dextral strike-slip occurred in the junction. (d) In E, TLF and GJF showed dextral strike-slip, XGF was characterized by NW-WNWtrending compressive fracturing. $F_{1}$. Xiangfan-Guangji fault; $F_{2}$. Tanlu fault; $F_{3}$. Ganjiang Fault.

\section{Moment tensor solution}

\subsection{Moment tensor inversion method}

In general, a common method applied in focal mechanism determination is $\mathrm{P}$ wave initial polarity analysis and waveform inversion. In recent years, the latter has been widely used.

Seismic source can be represented by a moment tensor $\boldsymbol{M}$ with six independent elements. Then the synthetic seismogram can be calculated by the linear combination of the six terms and the corresponding Green's function (Kikuchi and Kanamori, 1991).

In this study, to obtain stable moment tensor solutions, simple point source model is assumed. In addition, focal mechanism is kept constant during an earthquake, and source time function is an isosceles triangle with half duration. The best solution is obtained by minimizing the difference between the observed and the synthetic seismograms (Aki and Richards, 1980).

$$
\sigma=\frac{\left(W^{\mathrm{obs}}-W^{\mathrm{syn}}\right)^{2}}{\left(W^{\mathrm{obs}}\right)^{2}}=\frac{\sum(\boldsymbol{d}-\boldsymbol{A} \boldsymbol{m})^{2}}{\sum \boldsymbol{d}^{2}}
$$

where $\boldsymbol{d}$ is data vector, $\boldsymbol{A}$ is a coefficient matrix, and $\boldsymbol{m}$ is a model parameter vector. $W^{\text {obs }}$ and $W^{\text {syn }}$ are the observed waveform and synthetic waveform; variance, $\sigma$, is used for evaluation of the results.

\subsection{Data and data processing}

In this paper, local seismic data with high signalto-noise-ratio recorded by CDSN network are used to calculate the moment tensor for the Ruichang-Yangxin earthquake. For the inversion, the proper epicenter distance ranges from $100 \mathrm{~km}$ to $500 \mathrm{~km}$. According to the principle mentioned above, totally eight broadband stations with good azimuth are chosen (Figure 2). Three components for each station are considered. The data are processed to mitigate the effect of the heterogeneity

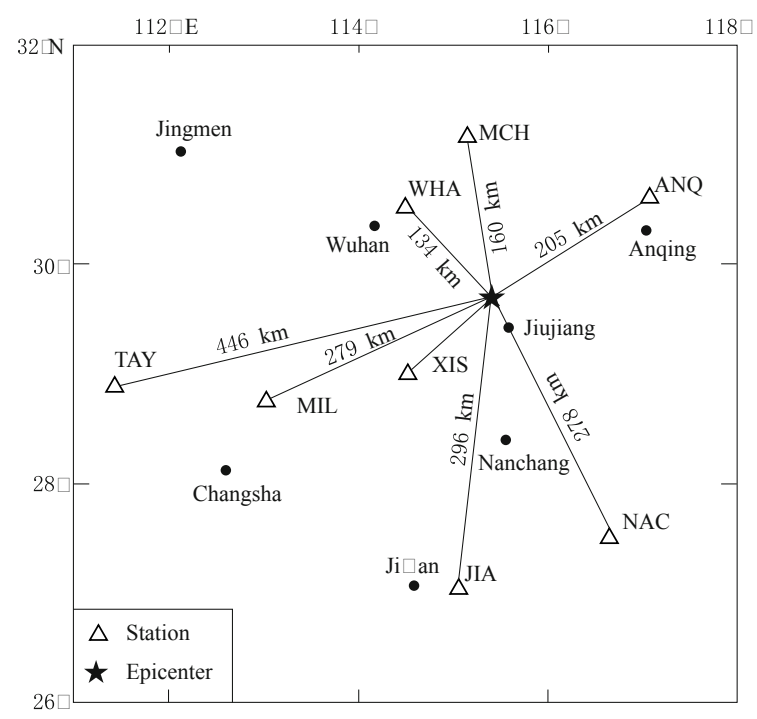

Figure 2 Distribution of seismic stations in the studied area. 
of the local velocity structure using four-order Butterworth band-pass filter. In addition, the data are resampled with the time interval of $0.05 \mathrm{~s}$. We select a proper filter ranging $0.02-0.05 \mathrm{~Hz}$ for the earthquake. For the Green's function calculation, we adopt the discrete wave number method developed by Kohketsu (1985) with an appropriate structure velocity model.

\subsection{Crustal velocity model in the studied area}

In order to get an appropriate assumed velocity model for the moment tensor inversion, this study analyzes different crustal structure models from CRUST2.0, IASPEI91 and others. CRUST2.0 specifies a $2^{\circ} \times 2^{\circ}$ grid, which takes advantage of a recent compilation of global sediment thickness on a $1^{\circ} \times 1^{\circ}$. For the studied area, the crustal profile available from the CRUST2.0 model is called the M5, which consists of four uniform layers with the Moho discontinuity at $31 \mathrm{~km}$ depth. And the IASPEI91 model consists of two uniform layers with the discontinuities at 20 and $35 \mathrm{~km}$ depth. The Moho depth differs about $4 \mathrm{~km}$ from that of the M5 model. And the MM model (Lü et al., 2008) has five uniform layers, which has the same Moho discontinuity at $35 \mathrm{~km}$ depth as the IASPEI91 model (Figure 3).

In order to choose the appropriate model, we check the effect of the variety of models on the travel-time difference of $\mathrm{P}$ - and $\mathrm{S}$-waves. By comparing the observed $\mathrm{S}-\mathrm{P}$ travel-time differences from five events with theoretical results, the model with minimum root mean square (RMS, equation (2)) is chosen as the optimized one.

$$
\mathrm{RMS}=\sqrt{\frac{\sum_{i=1}^{n}\left(W_{i}^{\mathrm{obs}}-W_{i}^{\mathrm{syn}}\right)^{2}}{n}}
$$

where $W_{i}^{\text {obs }}$ and $W_{i}^{\text {syn }}$ are the $i$-th observed value and calculated value, and $n$ is the total number of values.

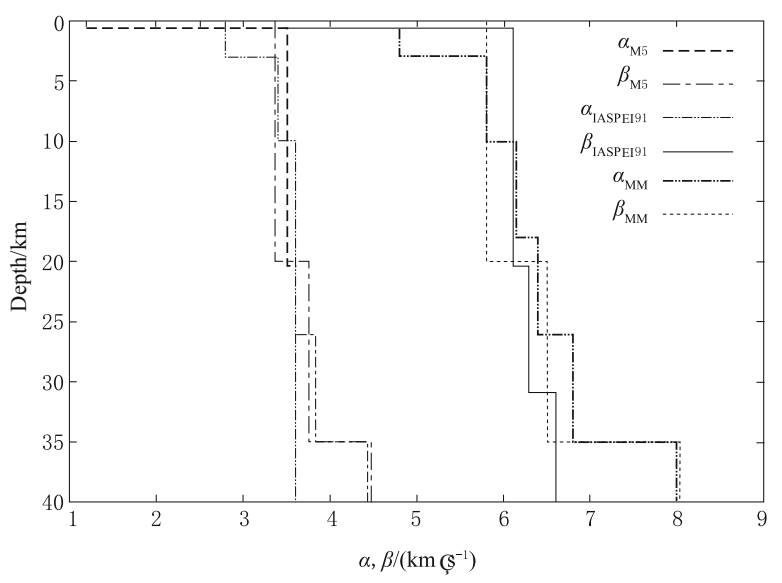

Figure 3 Comparison of velocity structure among the M5, IASPEI91 and MM models. $\alpha$ and $\beta$ stand for the $\mathrm{P}$ wave and $\mathrm{S}$ wave velocitiy, respectively.

From Table 1, it is easy to find that the minimum RMS value is given by the MM model. It suggests that this model predicts the behavior of the seismic velocity in the studied area and is more appropriate for the calculation of Green's function.

\subsection{Moment tensor inversion results}

By inversion, we obtain the best moment tensor solution of the Ruichang-Yangxin earthquake. Figure 4 shows the focal mechanism of this earthquake and the comparison between the observed (solid line) and the synthetic seismograms (dashed line) for the event.

Table 1 Comparison of the observed S-P travel times and the theoretical ones using M5, IASPEI91 and MM models

\begin{tabular}{|c|c|c|c|c|c|c|c|c|c|}
\hline \multicolumn{2}{|c|}{ Origin time } & \multicolumn{2}{|c|}{ Epicenter } & \multirow[b]{2}{*}{ Depth/km } & \multirow[b]{2}{*}{$M_{\mathrm{L}}$} & \multicolumn{4}{|c|}{$\mathrm{S}-\mathrm{P}(\mathrm{s})$ travel time } \\
\hline $\begin{array}{c}\text { Data } \\
\text { a-mo-d }\end{array}$ & $\begin{array}{c}\text { Time } \\
\text { h:min:s }\end{array}$ & $\begin{array}{l}\text { Lat. } \\
/{ }^{\circ} \mathrm{N}\end{array}$ & $\begin{array}{l}\text { Long. } \\
/{ }^{\circ} \mathrm{E}\end{array}$ & & & Obs. & M5 & IASPEI91 & MM \\
\hline 2011-09-10 & $15: 35: 21$ & 29.68 & 115.43 & 8.0 & 3.0 & 6.94 & 7.10 & 7.10 & 6.95 \\
\hline 2011-09-10 & $23: 41: 06$ & 29.73 & 115.47 & 9.0 & 2.2 & 6.85 & 6.74 & 6.72 & 6.69 \\
\hline 2011-09-11 & $00: 20: 28$ & 29.72 & 115.45 & 6.0 & 2.3 & 6.89 & 6.90 & 6.88 & 6.77 \\
\hline 2011-09-11 & $05: 44: 48$ & 29.72 & 115.47 & 4.0 & 2.3 & 6.95 & 6.65 & 6.62 & 6.58 \\
\hline 2011-09-11 & $11: 11: 44$ & 29.70 & 115.43 & 6.0 & 2.1 & 6.85 & 7.10 & 7.09 & 6.96 \\
\hline \multicolumn{4}{|c|}{ RMS for each model } & & & & 0.196 & 0.206 & 0.195 \\
\hline
\end{tabular}

The moment tensor solution is as follows: for nodal plane I, strike $302.2^{\circ}$, dip $68.2^{\circ}$, slip angle $-3.8^{\circ}$; and for nodal plane II, strike $33.6^{\circ}$, dip $86.5^{\circ}$, slip angle $-158.1^{\circ}$. The variance is 0.24 and moment magnitude is $M_{\mathrm{W}} 4.0$. By comparison, most of the observed seismograms fit well with the synthetic ones. The moment tensor solution is robust. 


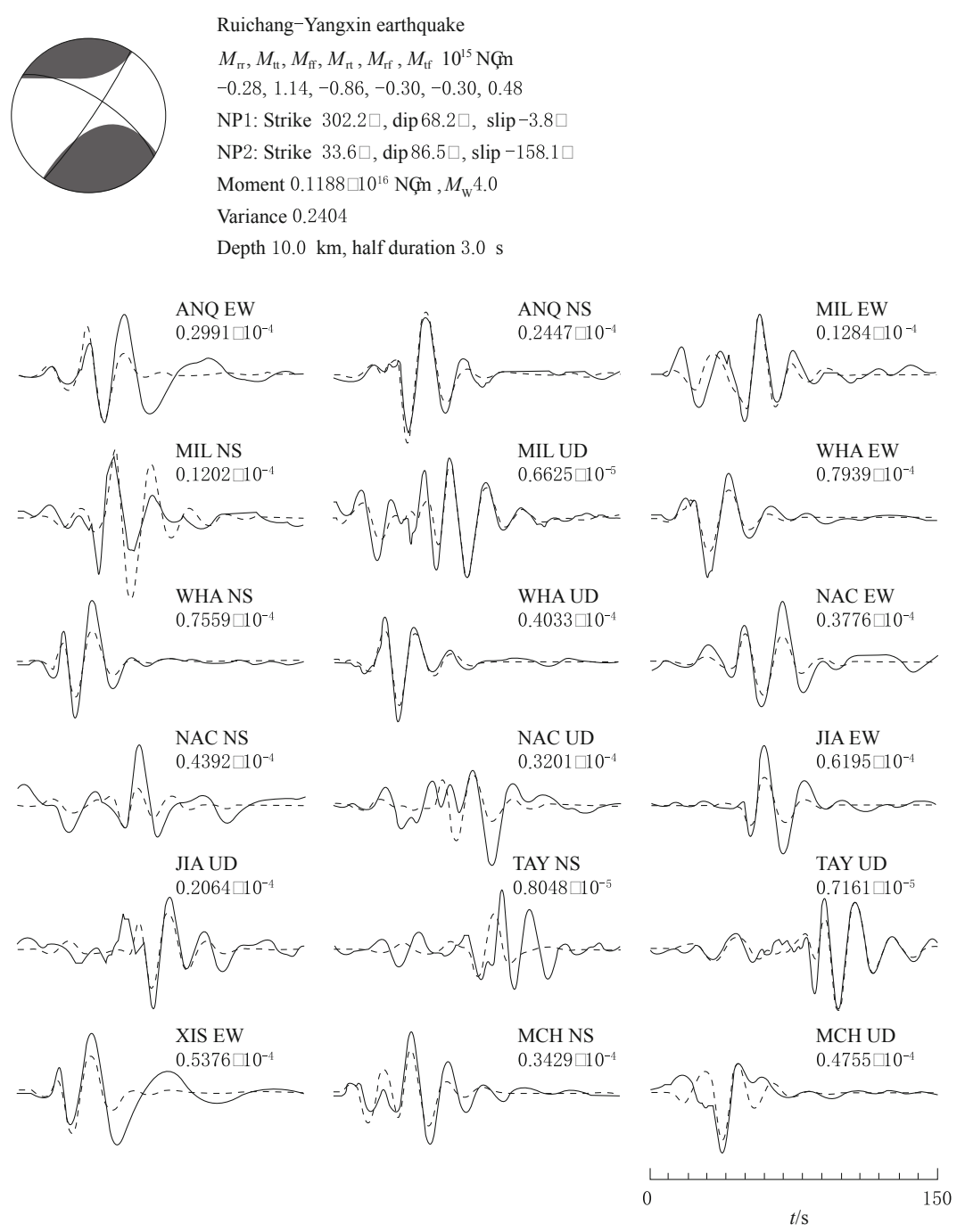

Figure 4 Moment tensor solution for Ruichang-Yangxin mainshock and comparison between observed (solid lines) and synthetic (dashed lines) seismograms.

\section{Discussion on seismogenic struc- ture}

\subsection{Earthquake distribution}

Till 30 September 2011, totally 68 aftershocks were recorded, and the maximum magnitude is $M 3.0$. We adopted the double-difference method to relocate all these aftershocks. Earthquake precise relocation results show that the Ruichang-Yangxin mainshock occurred in the southwestern area of NE-trending fault (Figure 5b). Field investigation demonstrates that along the NEtrending major-axis of isoseismal, seismic wave attenu- ates slowly, indicating that the Ruichang-Yangxin mainshock is perhaps controlled by the NE-trending fault.

It can be seen from Figure $5 \mathrm{~b}$ that the aftershocks distribute along the NE-trending fault and its conjugate NW-trending fault. To some extent, it indicates that this earthquake has close relationship with the NWtrending fault as well. As is well known, on 26 November 2005, the Jiujiang-Ruichang M5.7 earthquake also occurred in this area. From the spatial distribution of this earthquake, the conjugated interaction of the two groups of faults can be obviously found as well (Figure 5a). Therefore, the junction area should be paid more attention to. 

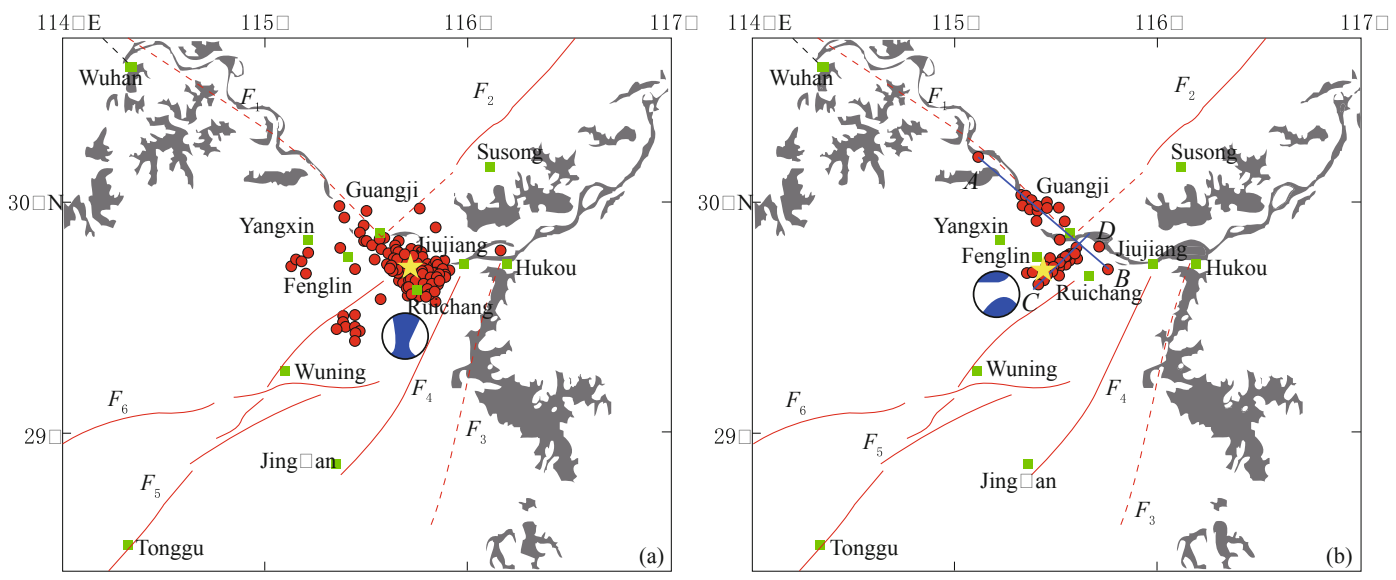

Figure 5 Spatial distribution of the mainshock (denoted by asterisk) and aftershocks (denoted by red dots) for Jiujiang-Ruichang earthquake (a) and Ruichang-Yangxin earthquake (b). The moment tensor solution in (a) is from Harvard. $F_{1}$. Xiangfan-Guangji fault; $F_{2}$. Tanlu fault; $F_{3}$. Ganjiang fault; $F_{4}$. Jiujiang-Jing'an fault; $F_{5}$. Ruichang-Wuning-Tonggu fault; $F_{6}$. Gushi-De'an fault. Blue lines are $A B$ and $C D$ profiles.
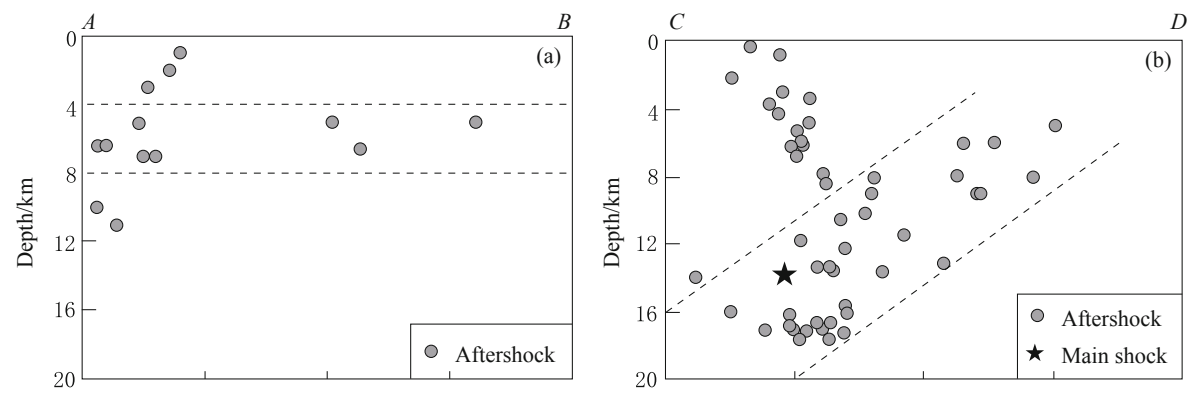

Figure 6 Profiles of focal depth along the cross sections $A B$ (a) and $C D$ (b).

Figure 6 gives the profiles of focal depth along two cross sections $A B$ and $C D$. For the profile $A B$ that is vertical to the NE-trending fault, there is no obvious characteristic in depth distribution. The earthquakes mainly distribute in the depth of $4-8 \mathrm{~km}$. Along the profile $C D$ that is vertical to the NW-trending fault, it is found that from $\mathrm{SW}$ to $\mathrm{NE}$, the focal depth changes from deep to shallow. If the NW-trending fault is the seismogenic structure of the Ruichang-Yangxin earthquake, according to the strike and dip of the fault, the earthquakes should mainly distribute along the NW direction and the focal depth should become deeper from SW to NE. However, it is contradictory to the analysis mentioned above. Therefore, we can infer that the NW-trending fault is not the seismogenic fault.

\subsection{Focal mechanism analysis}

Moment tensor solution of the Ruichang-Yangxin mainshock indicates that the strikes of the two nodal planes are NE and NW, which is consistent with earthquake relocation results. Nodal plane I with NEtrending has dextral strike slip with reverse component, and nodal plane II with NW-trending has sinistral strike slip with reverse component. From the moment tensor solution, we can deduce that under the compression of nearly east-western stress field, the NE-trending strike of the fault slipped right-laterally and pulled the NWtrending fault to rotate left-laterally. It is consistent with the stress field characteristics of near EW extrusion and near NS extension in this area.

\subsection{Regional structure characteristics}

Except for Tanlu fault (TLF) and XiangfanGuangji fault (XGF), there are some other regional active faul-ts in the studied area, such as JiujiangJing'an fault, Hukou-Xin'gan fault (a portion of Ganjiang fault), Ruichang-Wuning fault (Figure 5). These NE-trending faults have great influences on tectonic activities in this region. They are the main seismogenic structures in this area, which are responsible for the 
occurrence of moderate earthquakes (Li et al., 2008).

In terms of the location, the epicenter of the Ruichang-Yangxin mainshock is close to RuichangWuning fault, which is a dip-normal fault with NEstrike. However, as mentioned above, the focal mechanism of this earthquake shows that the two faultplanes are respectively dextral strike slip with reverse component and sinistral strike slip with reverse component, being inconsistent with the characteristics of the Ruichang-Wuning fault. Therefore, we infer that this earthquake is not caused by the Tanlu fault.

From the earthquake distribution (Figure 5b), we notice that the Ruichang-Yangxin earthquake swarm distributes along the TLF. According to the analysis on TLF above, it is known that this fault is a dextral strike-slip fault with reverse component. And this feature is in accordance with the focal mechanism result of the Ruichang-Yangxin earthquake.

\section{Conclusions}

Based on comprehensive analysis of earthquake distribution, characteristics of isoseismas, focal mechanism solutions and regional structure characteristics, we infer that the Ruichang-Yangxin earthquake is caused by Tanlu fault. In addition, many aftershocks distribute along the NW-trending buried fault. This indicates that this earthquake has close relationship with the NW-trending fault as well.

Therefore we speculate that under the influence of near E-W extrusion stress field, the Tanlu fault showed dextral strike slip. Consequently, it makes the NWtrending fault sinistral strike-slip. To some extent, it is the conjugate shear action that causes this earthquake. In recent years, many earthquakes have occurred along the NW-trending fault. It reminds us that the junction area is the earthquake-prone area, and should be paid more attention to. As for the question whether Tanlu fault extends southward and across Yangtze River or not, and whether the NW-trending buried fault is the south-eastern extension of Xiangfan-Guangji fault in Yangtze platform or not, more researches need to be done.

Acknowledgements We thank Prof. Y. Yagi for providing program and three anonymous reviewers for their great help and useful suggestion. This work was supported by the Director Foundation of Institute of Seismology, China Earthquake Adminstration (IS201102643) and National Nature Science Foundation of China (No. 41004020).

\section{References}

Aki K and Richards P G (1980). Quantitative Seismology: Theory and Methods. Freeman, San Francisco, 932pp.

Cui X J, Xia B, Zeng Z X, Liu L L, Chen X Y and Yang W R (2005). Junction between Ganjiang fault and Tanlu fault and its significance to mineralization. Geotectonica et Metallogenia 29(1): 1-12.

Kohketsu K (1985). The extended reflectivity method for synthetic near-field seismograms. J Phys Earth 33: 121131.

Kikuchi M and Kanamori H (1991). Inversion of complex body waves - III. Bull Seismol Soc Am 81: 2 335-2 350.

Li C Y, Zeng X F and Zhang J X (2008). Seismo-tectonic background and seismogenic structure of 2005 Jiujiang M5.7 earthquake in Jiangxi province. Chinese Science (Series D) 38(3): 343-354 (in Chinese with English abstract).

Lü J, Zheng Y and Ni S D (2008). Focal mechanisms and seismogenic structures of the $M_{\mathrm{S}} 5.7$ and $M_{\mathrm{S}} 4.8$ JiujiangRuichang earthquakes of Nov. 26, 2005. Chinese J Geophys 25(1): 158-164 (in Chinese with English abstract).

Tang J F, Li H K and Lou Q (2003). Progress in the study of the southern segment of the Tanlu fault and the discussion of the nature of the fault. Geological Bulletin of China 22(6): 426-436 (in Chinese with English abstract).

Wan G M, Tang L J, Jin W Z and Yu Y X (2009). Progresses and problems in the study of Tancheng-Lujiang fault zone. Geological Review 52(2): 251-259 (in Chinese with English abstract). 